\title{
The Effects of Parents' Humor Styles on Children's Emotional Regulation Competence -The Mediating Effect of Warm Parenting Behavior-
}

\author{
Yeon Kyeung $\mathrm{Oh}^{1}$, Hae Shin Hwang ${ }^{2}$ \\ Director, Nerisarang Educational Research Institute, Seoul, Korea ${ }^{1}$ \\ Professor, Department of Family Welfare, Sangmyung University, Seoul, Korea ${ }^{2}$ \\ 부모의 유머스타일이 유아의 정서 조절능력에 미치는 영향 \\ -온정적 양육행동의 매개효과를 중심으로- \\ 오연경 ${ }^{1}$, 황혜신 ${ }^{2}$ \\ 내리사랑교육연구소 소장 ${ }^{1}$, 상명대학교 가족복지학과 교수 ${ }^{2}$
}

Objectives: To investigate the effects of humor styles used by parents toward their children on the latter's emotion regulation competence, and the role of parents' warm parenting style in their relationships.

Methods: The parents' humor style and warm parenting behavior and their children's emotion regulation competence were measured in 153 children aged 5-6 years, attending child care centers and kindergartens located in Seoul and Gyeong-gi regions, along with their parents, totaling to 459 participants. The collected data were analyzed using factor analysis, multiple regression analysis, and regression mediation analysis, with SPSS 21.0 program.

Results: First, if the father used more social humor, or if the mother used more social and selfenhancing humor, the child was more likely to have high emotion regulation competence. Second, the parents using more social and self-enhancing humors and mothers using more aggressive humor were more likely to show warm parenting behavior. Third, the warm parenting behavior of the mother mediates the positive effect of her social and self-enhancing humor on her child's emotion regulation competence.

Conclusions: The frequent use of social and self-enhancing humor by parents means that they express their own emotion after regulating it positively. The infants adaptively regulate their own emotions by learning the regulated emotions of their parents. In addition, this result suggests that mother's parenting behaviors are more influential on the child's development than father's parenting behaviors, despite women's active advancement into society and change in values of child-rearing.

Keywords: humor style, warm parenting behavior, emotion regulation competence, parents' humor

\section{Introduction}

정서 조절능력이란 다양한 정서적 자극이 주어졌을 때 자신의

Corresponding Author: Hae Shin Hwang, Professor, Department of Family Welfare, Sangmyung University, 20, Hongjimun 2-gil, Jongno-gu, Seoul, Korea

E-mail: hshwang@smu.ac.kr
정서를 조절하여 반응하는 능력으로(Mayer \& Salovey, 1995), 정서 조절능력이 높은 유아는 협동적이며, 대인관계가 원활 하고(S. W. Lee, Moon, \& Kim, 2012), 문제행동을 덜 나타내는

(C)The Korean Association of Child Studies

This is an Open Access article distributed under the terms of the Creative Commons Attribution Non-Commercial License (http:// creativecommons.org/licenses/by-nc/4.0) which permits unrestricted noncommercial use, distribution, and reproduction in any medium, provided the original work is properly cited. 
(Eisenberg, Liew, \& Pidada, 2001) 등, 적응적 역할(I. S. Park \& Nam, 2015)을 한다. 반면, 정서 조절능력이 낮은 유아는 부정 적인 감정을 공격적으로 표출하는 외현화 문제행동을 나타내 거나(M. J. Kim, 2006), 위축 또는 우울한 정서를 나타내는 등, 내현화 문제를 보인다(Dodge \& Garber, 1991). 아울러 유아기 에 형성된 정서 조절능력은 유아기뿐 아니라 성인기 이후 개 인의 사회적 역량과 타인과의 관계를 수립하고 유지하는데 중요한 역할을 하며(Causey \& Dubow, 1992), 발달의 과정에 서 어떠한 경험을 하는가에 따라 개인차가 발생하게 되므로 (Thompson, 1994), 유아의 정서 조절능력에 영향을 미치는 환 경적 요인을 살펴보는 것은 중요한 의의를 지닌다.

선행연구에 의하면 유아의 정서 조절능력은 어머니의 정서 표현, 정서수용태도, 정서에 대한 지도 등 부모의 반응양식이 핵심적인 역할을 한다(H.-J. Choi \& Gwag, 2017; Morris, Silk, Steinberg, Myers, \& Robinson, 2007; S. J. Park, 2004; Yeo \& Lee, 2009). 또한 공통적으로 부모의 반응이 수용적, 긍정적, 온정 적일 때 유아의 정서조절 능력이 높아짐을 알 수 있는데, 구체 적으로는 부모의 긍정적인 정서표현과(Baek, 2002), 문제 해결 과정에서 나타나는 부모의 낙관성이 높을수록(Alegre, 2011) 유아의 정서 조절능력에 긍정적인 영향을 주었다. 이러한 결 과는 웃음을 수반하는 긍정적 정서표현이자 부정적인 상황을 긍정적인 관점으로 바라보는 유머와 같은 맥락에서 접근해 볼 수 있다(Hur, 2010; Y.-H. Kim, 2009).

일반적으로 유머는 웃음을 수반하여 나타나기 때문에 유머 와 웃음을 혼용하여 사용하지만(Shin, Kim, \& Lee, 2010), 유머 와 웃음은 개념적으로 다른 특성을 가진다. 우리가 누군가에 게 ‘유머러스하다’라고 표현할 때, 이는 그 사람이 웃음이 많다 는 것을 의미하는 것이 아니라 유머를 인지하고 표현하는 능력 이 뛰어나다는 것을 말한다. 웃음이 자극에 의한 생리적 행동인 반면, 유머는 인지적, 정서적 과정을 통해 나타나는 상위에 있 는 개념인 것이다(H. R. Park, 2001). 따라서 부모가 자녀와의 관 계에서 유머를 사용한다는 것은 자신의 감정을 그대로 표현하 는 것이 아니라 인지적 과정을 거쳐(McGhee, 1976) 풍자나 해 학, 비유를 통해 표현되는 조절된 정서임을 의미한다. 유머러스 한 부모는 문제를 해결하는 과정에서 유연한 사고를 할 수 있 는 모델이 되어 주고, 갈등상황에서 다양한 대안을 찾게 하여, 궁극적으로 유아의 정서 조절능력 발달에 도움을 주는 것이다.

한편, 유머를 자주 사용하는 부모는 지나칠 수 있는 일상의 소소한 일도 즐거운 관점으로 바라보기 때문에, 양육 상황에서 자녀의 말과 행동에 더욱 관심과 애정을 가지고 민감하게 반 응한다. 선행연구에 따르면, 사교적이고 외향적인 부모는 자녀
의 요구에 더욱 민감하고, 어머니의 긍정적 심리는 온정적 양 육행동을 높이는 요소로 작용하였다(Jeon \& Park, 1999; Son \& Park, 2011). 부모의 성격이나 정서와 같은 긍정적인 심리적 상 태가 바람직한 양육행동으로 이어지는 결정적인 요인인 것이 다(J.-Y. Kim \& Lee, 2011). 같은 맥락에서 유머 역시 외향성을 나타내는 성격적 특성이자, 긍정적인 정서를 표현하는 도구이 므로(Ha \& Kwon, 2011), 부모의 유머가 양육행동에 영향을 줄 수 있는 변인임을 시사한다.

실제로 유머감각이 높은 어머니는 사회적 양육행동과 긍정 적인 한계설정을 통해 바람직한 양육행동을 나타냈으며(J.-W. Lee \& Kang, 2014), 어머니가 유머를 인지하거나 즐기는 수준 이 높고, 유머나 웃음을 사용하여 문제 상황에 대처할수록 양 육스트레스가 낮았다(J. Y. Kim \& Chung, 2013). 온정적 양육 행동이란 애정적 양육행동, 수용적 양육행동과 동일한 개념으 로 사용되기도 하는데, 이들은 공통적으로 자녀와 정서적으로 밀착된 관계를 맺고, 자녀를 자애로운 태도로 대하며(J.-U. Lee, Choi, \& Bak, 2012), 칭찬과 격려로 긍정적 반응을 이끌어내는 특징을 가진다(J. H. Park, 2001). 따라서 부모의 온정적 양육행 동과 더불어 재미있는 표정이나 즐거움을 유발하는 유머가 함 께 표현된다면, 온정적 양육행동이 자녀의 발달에 미치는 효과 는 더욱 높아질 것이 예상된다.

아울러 온정적 양육행동은 유아의 긍정적인 정서 조절능력 을 예측하는 변인(Y. J. Lim, 2002)임이 꾸준히 보고되어 왔다. 선 행연구 결과를 살펴보면, 부모가 자녀의 요구를 지지하고 수용 하며, 자녀가 어머니의 양육행동을 애정적으로 지각할수록(H. S. Lim \& Park, 2002), 유아는 자신의 정서를 긍정적으로 조절하 였다. 반면, 부모가 유아의 행동을 비판하고 거부할 경우에는 정서를 표현하고 조절하는 능력이 낮아졌다(Kochanska, Aksan, \& Carlson, 2005). 부모로부터 받은 사랑과 수용의 경험은 관찰 되고 모방되며, 유아는 온정적인 부모의 모습을 통해 자신의 정 서 조절능력을 발달시켜 나가는 것이다. 한편, 기존의 연구들은 자녀와 많은 시간을 함께 보내는 어머니의 양육행동이 유아의 정서발달에 더욱 주요한 요인임을 주장해 왔다(Pett, VaughanCole, \& Wampold, 1994). 그러나 최근에는 아버지 양육에 관한 인식이 보편화 되고, 양육시간의 양적인 차이에도 불구하고, 부모의 양육행동이 자녀의 정서발달에 미치는 영향은 아버지 와 어머니가 각기 다른 고유의 영향을 주고 있음(Y. Lim \& Jin, 2015)이 보고됨에 따라 이를 살펴볼 필요성이 제기된다.

이에 따라 본 연구에서는 아버지와 어머니의 유머 스타일 이 유아의 정서 조절능력에 영향을 미치는 과정에서 부모의 온정적 양육행동이 각각 어떠한 역할을 하는지 밝힐 것이다. 
또한 부모의 양육 능력은 반복된 훈련을 통해 개발되므로(Teti \& Candelaria, 2005), 온정적 양육행동을 증진시키기 위한 구 체적인 방법으로 부모의 유머 사용을 제안하고자 한다.

이를 위해 본 연구에서 설정한 연구문제는 다음과 같다.

\section{연구문제 1}

부모의 유머 스타일이 유아의 정서 조절능력에 미치는 영향 은 어떠한가?

1-1. 아버지의 유머 스타일이 유아의 정서 조절능력에 미치는 영향은 어떠한가?

1-2. 어머니의 유머 스타일이 유아의 정서 조절능력에 미치는 영향은 어떠한가?

\section{연구문제 2}

부모의 유머 스타일이 온정적 양육행동에 미치는 영향은 어 떠한가?

2-1. 아버지의 유머 스타일이 온정적 양육행동에 미치는 영향 은 어떠한가?

\section{2-2. 어머니의 유머 스타일이 온정적 양육행동에 미치는 영향 은 어떠한가?}

\section{연구문제 3}

부모의 온정적 양육행동은 부모의 유머 스타일이 유아의 정 서 조절능력에 미치는 영향을 매개하는가?

3-1. 아버지의 온정적 양육행동은 부모의 유머 스타일이 유아 의 정서 조절능력에 미치는 영향을 매개하는가?

3-2. 어머니의 온정적 양육행동은 부모의 유머 스타일이 유아 의 정서 조절능력에 미치는 영향을 매개하는가?

\section{Methods}

\section{연구대상}

본 연구는 서울지역에 위치한 어린이집 1 개 기관과 경기지역
의 유치원 2 개 기관에 다니고 있는 유아 210 명과 그들의 아버 지와 어머니를 대상으로 이루어졌다. 부모의 유머가 유아의 정서조절능력에 미치는 영향을 살피기 위해서는 유아가 부모 의 유머를 이해해야 하므로, 부조화 상황에 대한 인지능력을 갖춘(J.-Y. Kim, 2004; Y.-H. Kim, 2009) 만5-6세 유아를 연구 대 상으로 하였다. 총 193 쌍의 질문지가 회수되었으며, 수집된 자료 중에서 불성실한 응답을 한 40 쌍의 자료를 제외한 후, 최 종적으로 유아 153 명, 아버지 153명, 어머니 153명, 총 459명 의 자료를 분석하였다.

Table 1에 제시한 연구 대상자의 사회 인구학적 특성을 살 펴보면, 유아 153명 중에서 만5세는 77명(50.3\%), 만6세는 76 명(49.7\%)이며, 성별은 남아 78명(51.0\%), 여아 75 명(49.0\%) 으로 나타났다.

Table 1

Demographic Characteristic

\begin{tabular}{llll}
\hline \multicolumn{1}{c}{ Variable } & Frequency (\%) & \multicolumn{1}{c}{ Variable } & Frequency (\%) \\
\hline Child's age (in years) & & Child's gender & \\
5 & $77(50.3)$ & Male & $78(51.0)$ \\
6 & $76(49.7)$ & Female & $75(49.0)$ \\
\hline
\end{tabular}

\section{연구도구}

\section{부모의 유머 스타일}

부모의 유머 스타일은 Martin, Puhlik-Doris, Larsen, Gray와 Weir (2003)가 개발한 성인용 유머 스타일척도(Humor Styles Questionnaire [HSQ])를 수정하여 사용하였다. 부모용 유머 스 타일 척도의 하위요인은 사회적 유머 7문항, 자기확장 유머 7 문항, 공격적 유머 3 문항, 자기패배 유머 5 문항으로 구성된다.

사회적 유머란 부모자녀 관계를 친밀하게 하고 긴장을 해 소시키는 재미있는 이야기나 농담으로, 재미있는 소리를 반복 해서 표현하거나 스킨십을 통해 웃음 유발하는 등 자녀와 많 이 웃고 즐기는 상호작용을 의미한다. 자기확장 유머란 개인 내적인 부정적 정서를 최소화시키는 유머를 의미하는 것으로, 자녀와의 관계에서 유발되는 갈등 상황 보다는 즐거웠던 상호 작용을 떠올림으로써 자신의 기분을 긍정적으로 유지할 수 있 다. 공격적 유머는 부모가 자녀의 실수를 놀리거나 웃음거리 로 만드는 부적응적 유머로서, 자녀의 행동을 우스꽝스럽게 묘사하거나 유머를 이용하여 지적하는 것 등을 들 수 있다. 자 기패배 유머는 부모가 자신을 낮추고 비하하여 웃음의 대상이 
되는 유머로서, 구체적으로는 자녀가 떼를 쓸 때 재미있는 표 정을 지어 웃음을 유발하거나, 부모를 놀리는 등 무례한 행동 을 보일 때에도 자녀가 원한다면 때와 장소를 가리지 않고 유 머를 표현하는 등의 행동을 포함한다.

본 척도의 타당도 검증을 위해 탐색적 요인분석을 하였는 데, 성인용 유머스타일 척도를 기준으로 요인의 수는 4 로 설정 하고, 공통성 .4이하의 항목을 제거하였다. 이후 베리멕스 회 전을 실시한 결과 최종적으로 네 개의 하위요인 총 22 문항이 구성되었다. 각 문항은 전혀 그렇지 않다(1점)에서 매우 그렇 다(5점)의 Likert식 5점 척도로 평가하며, 각 영역의 점수가 높 을수록 해당하는 요인의 유머 스타일을 많이 사용하는 것을 의미한다. 본 연구에서 산출된 내적합치도 계수는 .83 이었고, 하위요인별로는 사회적 유머 .84, 자기확장 유머 .82, 공격적 유머.59, 자기패배 유머.72로 나타났다.

\section{유아의 정서 조절능력}

유아의 정서 조절능력을 측정하기 위해 Shield와 Cicchetti (1997)의 정서조절 체크리스트(Emotion Regulation Checklist [ERC])를 번안한 J. Y. Kim (2007)의 척도를 사용하였다. 이 척 도는 유아의 적응적 정서조절(adaptive emotion regulation)과 불안정/부정성 정서(lability/negativity)를 측정하기 위한 것으 로 부모가 평정하며, 총 24문항으로 구성되어 있다. 각 문항은 전혀 그렇지 않다(1점)에서 매우 그렇다(4점)까지 4점 Likert 척도로 평가하며, 적응적 정서조절 점수가 높을수록, 불안정/ 부정성 점수가 낮을수록 유아의 정서 조절능력이 높은 것을 의미한다. 본 연구에서 산출된 내적합치도 계수는 적응적 정 서조절.74, 불안정/부정성 정서.84로 나타났다.

\section{부모의 온정적 양육행동}

부모의 온정적 양육행동을 측정하기 위해 Baumrind (1973)의 모델에 근거하여 B. H. Cho, Lee, Lee와 Kwon (1999)이 제작한 양육행동 측정 도구 중에서 온정적 양육행동 척도를 사용하였 다. 이 척도는 총 20 문항으로 구성되며, 각 문항은 전혀 그렇 지 않다(1점)에서 매우 그렇다(5점)의 Likert식 5점 척도로 평 가되며, 점수가 높을수록 온정적 양육행동을 많이 나타내는 것으로 해석한다. 본 연구에서 산출된 온정적 양육행동의 내 적합치도 계수는 .90 으로 나타났다.

\section{연구절차}

본 연구는 부모용 유머 스타일 척도의 타당도를 검증하고, 연 구과정의 오류를 줄이기 위해 2차 예비조사를 실시하였다. 예 비조사는 본 조사의 연구대상이 아닌 2 개의 어린이집에서 만 5-6세 자녀를 둔 부모님과 유아를 대상으로 하였다. 본 조사는 2016년 9월 20일부터 2016년 10월 21일까지 서울지역에 위치 한 어린이집 1 개 기관과 경기지역의 유치원 2 개 기관에 다니 고 있는 유아 210 명과 그들의 아버지와 어머니를 대상으로 이 루어졌다.

\section{1차 예비조사}

1 차 예비조사는 서울에 위치한 1개의 어린이집에서 만 5-6세 자녀를 둔 부모 40 명을 대상으로 진행하였다. 예비조사에서 수집된 자료는 요인분석을 실시하여 척도의 타당성을 검증하 였으며, 요인분석 결과를 토대로 2 차 예비조사의 척도를 재구 성하였다.

\section{2차 예비조사}

2차 예비조사는 2016년 7월 19일부터 21일까지 3일간 진행되 었으며, 서울에 위치한 1개의 어린이집에서 만 5-6세 자녀를 둔 부모 38 쌍과 자녀 38 명을 대상으로 진행하였다.

\section{본 조사}

본 조사는 2016년 9월 20일부터 2016년 10월 21일까지 서울, 경기지역에 위치한 어린이집과 유치원에서 실시되었다. 부모 의 유머 스타일과 온정적 양육행동은 아버지와 어머니가 각각 응답하도록 안내하였으며, 유아의 정서 조절능력은 주 양육자 가 응답하거나 부모가 함께 자녀의 행동을 관찰하여 응답하도 록 하였다. 질문지는 연구대상자의 정보보호를 위해 일련번호 를 기재한 후 연구 참여 동의서를 함께 배부하였으며, 수집된 내용은 각 가정에 결과보고서로 제공하였다.

\section{자료분석}

수집된 자료는 SPSS 21.0 (IBM Co., Armonk, NY) 프로그램을 이용하여 기초통계 산출 및, 탐색적 요인분석과 Cronbach's $\alpha$ 검증, Pearson의 상관분석을 실시하였다. 부모의 유머 스타일 
이 유아의 정서 조절능력 및 부모의 온정적 양육행동에 미치 는 영향을 살피고자 위계적 회귀분석을 실시하였으며, 부모의 유머 스타일과 유아의 정서 조절능력의 관계에서 온정적 양육 행동의 매개효과를 알아보기 위해 Baron과 Kenny (1986)가 제 시한 3단계 회귀분석과 Sobel test를 검증하였다.

\section{Results}

\section{부모의 유머 스타일이 유아의 정서조절능력에 미치는 영향}

부모의 유머 스타일이 유아의 정서 조절능력에 미치는 영향을 분석하기 위하여, 아버지와 어머니의 사회 인구학적 변인을 통제한 후에 위계적 회귀분석을 실시하였다. 회귀모형의 적합 성을 검증한 결과, 공차한계는 0.8 이상이며, $\mathrm{VIF}$ 값은 1.1 이하 로 다중공선성의 문제는 나타나지 않았으며, Durbin-Watson의
값은 $1.8 \sim 2.0$ 수준으로 잔차 독립성이 검증되었다. 분석결과 를 살펴보면, Table 2 와 같이 아버지의 사회적 유머는 유아의 정서 조절능력을 예측 $(\beta=.32, p<.001)$ 하는 변인이며, 모형 설명력은 $12 \%$ 로 나타났다. 한편, 아버지의 자기확장 유머, 공 격적 유머, 자기패배 유머는 유아의 정서 조절능력에 유의한 영향을 미치지 않았다.

다음으로 어머니의 유머 스타일이 유아의 정서 조절능력에 미치는 영향력을 살펴본 결과, Table 3과 같이 어머니의 사회적 유머 $\beta=.40, p<.001)$ 와 어머니의 자기확장 유머 $(\beta=.24, p<$ .01)는 유아의 정서 조절능력에 유의한 영향을 주었으며, 공격 적 유머와 자기패배 유머는 유의한 영향을 미치지 않았다.

\section{부모의 유머 스타일이 온정적 양육행동에 미 치는 영향}

부모의 유머 스타일이 온정적 양육행동에 미치는 영향력을 알 아보기 위하여 부모의 사회 인구학적 변인을 통제한 상태에서

Table 2

The Effects of Fathers' Humor Style on Children's Emotion Regulation Competence

\begin{tabular}{|c|c|c|c|c|c|c|}
\hline \multirow[b]{3}{*}{ Variable } & \multicolumn{6}{|c|}{ Affiliative humor } \\
\hline & \multicolumn{3}{|c|}{ Model1 } & \multicolumn{3}{|c|}{ Model2 } \\
\hline & $B$ & $S E$ & $\beta$ & $B$ & $S E$ & $\beta$ \\
\hline Age & .02 & .17 & .01 & 7.05 & .17 & .02 \\
\hline Education completed $^{\mathrm{a})}$ & 1.12 & .73 & .13 & .91 & .70 & .10 \\
\hline Income & -.18 & .38 & -.04 & -.26 & .36 & -.06 \\
\hline Humor styles & & & & 4.07 & 1.03 & $.32^{* * *}$ \\
\hline$F$ & \multicolumn{3}{|c|}{.81} & \multicolumn{3}{|c|}{$4.53^{* *}$} \\
\hline$R^{2}$ & \multicolumn{3}{|c|}{.01} & \multicolumn{3}{|c|}{.12} \\
\hline
\end{tabular}

a) high school $=1$, college $=2$, university $=3$.

${ }^{* *} p<.01 .{ }^{* * *} p<.001$.

Table 3

The Effects of Mothers' Humor Style on Children's Emotion Regulation Competence

\begin{tabular}{|c|c|c|c|c|c|c|c|c|c|c|c|c|}
\hline \multirow[b]{3}{*}{ Variable } & \multicolumn{6}{|c|}{ Affiliative humor } & \multicolumn{6}{|c|}{ Self-enhancing humor } \\
\hline & \multicolumn{3}{|c|}{ Model1 } & \multicolumn{3}{|c|}{ Model2 } & \multicolumn{3}{|c|}{ Model1 } & \multicolumn{3}{|c|}{ Model2 } \\
\hline & $B$ & $S E$ & $\beta$ & $B$ & $S E$ & $\beta$ & $B$ & $S E$ & $\beta$ & $B$ & $S E$ & $\beta$ \\
\hline Age & -.00 & .18 & -.00 & .20 & .18 & .09 & -.02 & .18 & -.01 & .03 & .18 & .01 \\
\hline Education completed $^{\text {a) }}$ & 1.53 & .75 & $.17^{*}$ & .62 & .72 & .07 & 1.50 & .75 & $.17^{*}$ & 1.14 & .74 & .13 \\
\hline Income & -.35 & .36 & -.08 & -.30 & .33 & -.07 & -.35 & .36 & -.08 & -.46 & .35 & -.11 \\
\hline Humor styles & & & & 5.01 & 1.00 & $.40^{* * *}$ & & & & 2.99 & 1.01 & $.24^{* *}$ \\
\hline$F$ & & 1.43 & & & 7.44 & & & 1.38 & & & 3.27 & \\
\hline$R^{2}$ & & .02 & & & .17 & & & .02 & & & .08 & \\
\hline
\end{tabular}

a) high school $=1$, college $=2$, university $=3$.

${ }^{*} p<.05{ }^{* *} p<.01$. ${ }^{* * *} p<.001$. 
Table 4

The Effects of Fathers' Humor Style on Warm Parenting Behavior

\begin{tabular}{|c|c|c|c|c|c|c|c|c|c|c|c|c|}
\hline \multirow{3}{*}{ Variable } & \multicolumn{6}{|c|}{ Affiliative humor } & \multicolumn{6}{|c|}{ Self-enhancing humor } \\
\hline & \multicolumn{3}{|c|}{ Model1 } & \multicolumn{3}{|c|}{ Model2 } & \multicolumn{3}{|c|}{ Model1 } & \multicolumn{3}{|c|}{ Model2 } \\
\hline & $B$ & $S E$ & $\beta$ & $B$ & $S E$ & $\beta$ & $B$ & $S E$ & $\beta$ & $B$ & $S E$ & $\beta$ \\
\hline Age & .31 & .22 & .12 & .36 & .18 & .14 & .25 & .22 & .09 & .22 & .21 & .08 \\
\hline Education completed $^{\mathrm{a})}$ & .51 & .93 & .04 & -.02 & .79 & -.00 & .60 & .96 & .05 & .20 & .93 & .01 \\
\hline Income & .59 & .49 & .10 & .37 & .41 & .06 & .58 & .50 & .10 & .70 & .48 & .12 \\
\hline Humor styles & & & & 8.19 & 1.15 & $.53^{* * *}$ & & & & 4.23 & 1.24 & $.29^{* *}$ \\
\hline$F$ & \multicolumn{3}{|c|}{1.39} & \multicolumn{3}{|c|}{$14.11^{* * *}$} & \multicolumn{3}{|c|}{1.131} & \multicolumn{3}{|c|}{$3.80^{* *}$} \\
\hline$R^{2}$ & \multicolumn{3}{|c|}{.03} & \multicolumn{3}{|c|}{.31} & \multicolumn{3}{|c|}{.026} & \multicolumn{3}{|c|}{.10} \\
\hline
\end{tabular}

a) high school $=1$, college $=2$, university $=3$.

${ }^{* *} p<.01 .{ }^{* * *} p<.001$.

Table 5

The Effects of Mothers' Humor Style on Warm Parenting Behavior

\begin{tabular}{|c|c|c|c|c|c|c|c|c|c|c|c|c|c|c|c|c|c|c|}
\hline \multirow[b]{3}{*}{ Variable } & \multicolumn{6}{|c|}{ Affiliative humor } & \multicolumn{6}{|c|}{ Self-enhancing humor } & \multicolumn{6}{|c|}{ Aggressive humor } \\
\hline & \multicolumn{3}{|c|}{ Model1 } & \multicolumn{3}{|c|}{ Model2 } & \multicolumn{3}{|c|}{ Model1 } & \multicolumn{3}{|c|}{ Model2 } & \multicolumn{3}{|c|}{ Model1 } & \multicolumn{3}{|c|}{ Model2 } \\
\hline & $B$ & $S E$ & $\beta$ & $B$ & $S E$ & $\beta$ & $B$ & $S E$ & $\beta$ & $B$ & $S E$ & $\beta$ & $B$ & $S E$ & $\beta$ & $B$ & $S E$ & $\beta$ \\
\hline Age & -.41 & .24 & -.14 & -.00 & .20 & -.00 & -.43 & .24 & -.14 & -.30 & .23 & -.10 & -.38 & .24 & -.13 & -.41 & .24 & -.14 \\
\hline Education completed ${ }^{a}$ & 2.55 & .96 & $.23^{* *}$ & .73 & .81 & .06 & 2.73 & .95 & $.24^{* *}$ & 2.12 & .92 & $.19^{*}$ & 2.44 & .97 & $.22^{*}$ & 2.32 & .95 & $.21^{*}$ \\
\hline Income & .19 & .46 & .03 & .30 & .37 & .05 & .24 & .46 & .04 & -.016 & .44 & -.00 & .25 & .47 & .04 & .32 & .46 & .06 \\
\hline Humor styles & & & & 9.53 & 1.11 & $.60^{* * *}$ & & & & 5.098 & 1.29 & $.31^{* * *}$ & & & & -2.48 & 1.03 & $-.19^{*}$ \\
\hline$F$ & & 3.45 & & & 22.14 & & & $4.02^{*}$ & & & $7.19^{*}$ & & & $3.22^{*}$ & & & $3.95^{*}$ & \\
\hline$R^{2}$ & & .07 & & & .39 & & & .08 & & & .17 & & & .06 & & & .10 & \\
\hline
\end{tabular}

a) high school $=1$, college $=2$, university $=3$.

${ }^{*} p<.05 .{ }^{* *} p<.01 .{ }^{* * *} p<.001$.

위계적 회귀분석을 실시하였다. 공차한계는 0.8 이상, VIF 값 은 1.1 이하로 다중공선성 문제는 나타나지 않았으며, DurbinWatson 결과의 값이 $1.9 \sim 2.3$ 수준으로 회귀모형이 정상분포곡 선을 이루고 있음을 확인하였다. 먼저 Table 4를 살펴보면, 아버 지의 사회적 유머 $(\beta=.53, p<.001)$ 와 자기확장 유머 $(\beta=.29, p<$ $.01)$ 는 각각 온정적 양육행동에 유의미한 영향을 주었다.

다음으로 어머니의 유머 스타일이 온정적 양육행동에 미치 는 영향에 관한 분석 결과를 살펴본 결과는 Table 5 와 같다. 분 석결과, 어머니의 사회적 유머 $(\beta=.60, p<.001)$ 는 온정적 양 육행동을 예측하는 변인으로써 모형의 설명력은 1 단계보다 $32 \%$ 증가하였다. 또한 어머니의 자기확장 유머 $\beta=.31, p<$ .001)도 온정적 양육행동을 설명하는 변인이며, 모형의 설명 력은 $17 \%$ 으로 나타났다. 반면 어머니의 공격적 유머는 온정 적 양육행동을 감소 $(\beta=-.19, p<.01)$ 시키는 요인임이 확인되 었다.

\section{부모의 유머 스타일이 유아의 정서 조절능력에 미치는 영향에 대한 온정적 양육행동의 매개효과}

부모의 유머 스타일이 유아의 정서 조절능력에 미치는 영향에 대한 온정적 양육행동의 매개효과를 알아보기 위하여 Baron과 Kenny (1986)가 제시한 회귀매개분석을 실시하였다. 분석결과 아버지의 유머스타일이 유아의 정서조절능력에 미치는 영향 은 온정적 양육행동의 매개효과가 나타나지 않았다. 반면, 어 머니의 사회적 유머와 자기확장 유머는 온정적 양육행동을 통 해 유아의 정서조절능력에 영향을 주는 것으로 나타났다.

구체적으로 살펴보면, Table 6 과 같이 1 단계에서 어머니의 사회적 유머는 유아의 정서 조절능력에 유의한 영향을 나타냈 으며 $(\beta=.40, p<.001), 2$ 단계에서 어머니의 사회적 유머가 온 정적 양육행동에 미치는 영향이 유의하였다 $(\beta=.60, p<.001)$. 다음으로 3단계에서 독립변수와 매개변수가 함께 투입되었을 때 모형의 설명력은 $23 \%$ 로 $R^{2}$ 값이 $6 \%$ 증가하였으며, 어머니 
Table 6

Warm Parenting Behavior as a Mediator of the Relationship Between Mothers' Affliative Humor and Children's Emotion Regulation Competence

\begin{tabular}{|c|c|c|c|c|}
\hline & Variable & $\beta$ & $R^{2}$ & $F$ \\
\hline 1 & Affiliative humor $\rightarrow$ Emotion regulation competence & $.40^{* * *}$ & .17 & $7.44^{* * *}$ \\
\hline 2 & Affiliative humor $\rightarrow$ Warm parenting behavior & $.60^{* * *}$ & .39 & $22.14^{* * *}$ \\
\hline \multirow[t]{2}{*}{3} & Affiliative humor $\rightarrow$ Emotion regulation competence & $.21^{*}$ & .23 & $7.96^{* * *}$ \\
\hline & Warm parenting behavior $\rightarrow$ Emotion regulation competence & $.31^{* *}$ & & \\
\hline
\end{tabular}

${ }^{*} p<.05 .{ }^{* *} p<.01 .{ }^{* * *} p<.001$.

Table 7

Sobel Test: Warm Parenting Behavior as a Mediator of the Relationship Between Mothers' Affliative Humor and Children's Emotion Regulation Competence

\begin{tabular}{|c|c|c|c|}
\hline Variable & $B$ & $S E$ & $Z$ \\
\hline Affiliative humor $\rightarrow$ Warm parenting behavior & 9.532 & 1.118 & $4.537^{* * *}$ \\
\hline Warm parenting behavior $\rightarrow$ Emotion regulation competence & .343 & .064 & \\
\hline
\end{tabular}

*** $p<.001$.

Table 8

Warm Parenting Behavior as a Mediator of the Relationship Between Mothers' Self-Enhancing Humor and Children's Emotion Regulation Competence

\begin{tabular}{|c|c|c|c|c|}
\hline & Variable & $\beta$ & $R^{2}$ & $F$ \\
\hline 1 & Self-enhancing humor $\rightarrow$ Emotion regulation competence & $.24^{* *}$ & .08 & $3.27^{*}$ \\
\hline 2 & Self-enhancing humor $\rightarrow$ Warm parenting behavior & $.31^{* * *}$ & .17 & $7.19^{* * *}$ \\
\hline & Warm parenting behavior $\rightarrow$ Emotion regulation competence & $.39^{* * *}$ & & \\
\hline
\end{tabular}

${ }^{*} p<.05 .{ }^{* *} p<.01 .{ }^{* * *} p<.001$.

의 사회적 유머가 유아의 정서 조절능력에 미치는 영향은 감 소하고 $(\beta=.21, p<.05)$, 매개변수인 어머니의 온정적 양육행 동이 종속변수에 미치는 영향은 유의하였다 $(\beta=.31, p<.01)$. 이는 어머니의 사회적 유머가 유아의 정서 조절능력에 미치는 영향이 어머니의 온정적 양육행동을 부분 매개하고 있음을 의 미한다.

아울러 부분 매개 효과의 크기를 살펴보면, 간접효과 $(\beta=$ .18) 보다 직접효과 $(\beta=.21)$ 의 영향력이 더욱 높은 것을 알 수 있다. Sobel test 결과치는 Table 7에 제시된 바와 같이 4.537로 검증기준인 1.96 이상이었으며, 유의도는 .001 수준에서 매개 효과의 유의성이 검증되었다. 즉, 어머니가 자녀와의 관계를 친밀하게 만들기 위해 재미있는 이야기를 많이 하고, 즐거운 상황을 자주 연출하는 것이 유아의 정서 조절능력을 직접적으 로 증가시킴과 동시에 어머니의 온정적 양육행동을 통해 간접 적으로 영향을 주기도 하는 것이다.

다음은 어머니의 자기확장 유머가 온정적 양육행동을 매
개로 유아의 정서 조절능력에 미치는 영향을 살펴본 것이다. Table 8 과 같이 1 단계에서 어머니의 자기확장 유머는 유아의 정서 조절능력을 높였으며 $(\beta=.24, p<.01), 2$ 단계에서 어머니 의 자기확장 유머는 어머니의 온정적 양육행동에 유의한 영향 을 주었다 $(\beta=.31, p<.001)$. 또한 3 단계에서 어머니의 자기확 장 유머와 온정적 양육행동을 함께 투입하였을 때, $R^{2}$ 의 설명 력이 $8 \%$ 에서 $20 \%$ 로 대폭 상승하였으며, 매개변수인 어머니 의 온정적 양육행동이 종속변수인 정서 조절능력에 미치는 영 향력 $(\beta=.39, p<.001)$ 은 유의한 반면, 어머니의 자기확장 유머 가 정서 조절능력에 미치는 영향력은 모두 사라지는 것을 알 수 있다. 또한 Sobel test를 실시한 결과는 Table 9와 같이 4.537 로 검증기준인 1.96 이상이었으며, 유의도는 .001 수준에서 매 개효과의 유의성이 검증되었다. 이는 어머니의 자기확장 유머 는 온정적 양육행동을 통해 간접적으로 유아의 정서조절능력 을 높이는 것으로 해석할 수 있다. 
Table 9

Sobel test: Warm Parenting Behavior as a Mediator of the Relationship Between Mother's Self-Enhancing Humor and Children's Emotion Regulation Competence

\begin{tabular}{lrrr}
\hline \multicolumn{1}{c}{ Variable } & $B$ & \multicolumn{1}{c}{$S E$} & $Z$ \\
\hline Self-enhancing humor $\rightarrow$ Warm parenting behavior & 9.532 & 1.118 & \multirow{2}{*}{$4.537^{* * *}$} \\
Warm parenting behavior $\rightarrow$ Emotion regulation competence & .343 & .064 & \\
\hline
\end{tabular}

${ }_{* * *} p<.001$.

\section{Discussion}

본 연구는 부모가 자녀에게 사용하는 유머 스타일이 유아의 정서 조절능력에 미치는 영향을 살피고, 이들의 관계에서 부 모의 온정적 양육행동이 어떠한 역할을 하는지 검증하는 것을 목적으로 다음과 같은 결론을 도출하였다.

첫째, 아버지가 사회적 유머를 많이 사용하고, 어머니가 사 회적 유머와 자기확장 유머를 많이 사용할수록 유아의 정서 조 절능력이 높다. 즉, 부모의 긍정적인 유머가 자녀의 정서 조절 능력을 증가시킨 것으로, 이는 다양한 이론적 측면에서 논의 해 볼 수 있다. 먼저 유머의 인지적 과정을 강조한 인지 부조화 이론(McGhee, 1976)에 따르면, 유머는 유머를 유발하는 부조 화 상황을 인식하고, 이를 간접적으로 표현하는 복잡한 인지적 과정을 거치게 된다. 따라서 유머러스한 부모는 문제 상황에서 즉흥적으로 자신의 감정을 표현하지 않고, 자신이 전달하고자 하는 내용을 비유적으로 표현할 것이다. 또한 유머의 정서적 반응을 강조한 각성이론(Freud, 1971)에 의하면, 유머는 갈등과 스트레스 상황에서 긴장과 불안을 감소시키는 역할을 하므로, 부모의 사회적 유머는 정서를 자극하는 다양한 상황에서 즐거 운 이야기와 농담으로 웃음을 유발하며, 자기확장 유머는 문 제를 긍정적인 관점에서 바라보게 할 것이다. 마지막으로 우월 성 이론(Martin, 2006)은 타인의 부족한 부분에 대한 반응으로 유머가 유발된다고 보는 것인데, 유머러스한 부모는 자녀가 실 수를 하거나 문제를 일으킨 상황에서 엄하게 가르치기보다 유 머를 활용하여 훈육의 메시지를 전달할 수 있다.

이와 같은 관점을 종합해볼 때, 부모가 사회적 유머와 자기 확장 유머를 자주 사용한다는 것은 부모가 자녀와의 문제 상 황에서도 자신의 정서를 긍정적으로 조절하여 표현함을 시사 한다. 따라서 유머를 자주 사용하는 부모의 자녀는 부모의 조 절된 정서를 학습하고, 갈등상황에서도 긴장감을 덜 느끼며, 보다 여유롭게 갈등해결을 위한 대안을 마련함으로써 궁극적 으로 자신의 정서 조절능력을 높여 나가는 것이다.

둘째, 아버지와 어머니가 사회적 유머와 자기확장 유머를 많이 사용하고, 어머니가 공격적 유머를 적게 사용할수록 온
정적 양육행동이 높다. 양육행동은 부모의 기질이나 정서 등, 개인적 변인에 의해 영향을 받는 요인이며(Belsky, 1984), 부모 의 유머 또한 부모 개인의 성격적인 특성을 의미하므로, 온정 적 양육행동에 영향을 준 것이다. 같은 맥락에서 자기확장 유 머는 부모 개인의 내적 유머이므로 양육 상황에서 발생하는 스트레스나 부정적인 사건을 긍정적으로 해석하게 함으로써 온정적인 양육행동을 증가시킨 것으로 사료된다.

이러한 결과는 부모의 유머가 온정적 양육행동을 예측하는 주요한 변인임을 확인한 것이다. 그동안 부모의 온정적 양육 행동이 유아의 발달에 지대한 영향을 미치는 것으로 보고되었 으며, 부모의 양육 능력은 반복된 훈련을 통해 개발(Douglas \& Margo, 2002)될 수 있으므로, 바람직한 유머 사용에 관한 부모교 육을 통해 온정적 양육행동의 효과를 증진시킬 수 있을 것이다.

셋째, 아버지의 사회적 유머는 온정적 양육행동을 매개하 지 않은 반면, 어머니의 사회적 유머와 자기확장 유머는 어머 니의 온정적 양육행동을 통해 유아의 정서 조절능력을 증가시 킨다. 구체적으로 어머니의 사회적 유머는 유아의 정서 조절 능력에 직접적인 영향을 줌과 동시에 어머니의 온정적 양육 행동을 통해 간접적인 영향을 준다. 상대적인 영향력은 어머 니의 사회적 유머가 유아의 정서 조절능력에 미치는 영향보 다 어머니의 온정적 양육행동이 유아의 정서 조절능력에 미치 는 영향이 더욱 높다. 또한 자기확장 유머가 유아의 정서조절 능력에 미치는 영향은 어머니의 온정적 양육행동이 완전매개 함으로써 간접적인 영향만 주고 있음을 알 수 있는데, 이는 유 아의 정서조절 능력이 어머니의 유머 보다 온정적 양육행동의 영향을 더욱 많이 받고 있음을 의미한다.

주목할 점은 아버지와 어머니의 유머 모두 유아의 정서조 절 능력을 높임으로써 동일한 양상을 나타냈지만, 온정적 양 육행동의 매개효과는 상이한 결과가 나타난 점이다. 구체적으 로 아버지의 온정적 양육행동은 매개효과가 나타나지 않은 반 면, 어머니의 온정적 양육행동은 매개효과가 나타났는데, 이 와 같은 결과는 사회구조의 변화와 함께 여성의 사회진출이 활발해지고, 자녀 양육에 대한 가치관이 변화하고 있음에도 불구하고, 여전히 어머니의 양육행동이 아버지의 양육행동보 
다 자녀의 발달에 많은 영향을 주고 있음을 시사한다. 실제로 오늘날의 아버지들은 이전 세대보다 자녀 양육에 대한 관심 이 높지만, 양육에 참여하는 시간은 어머니에 비해 극히 저조 한 것으로 나타났다(Y. Lee, Kim, \& Lim, 2016). 이는 본 연구결 과에서 나타난 아버지와 어머니의 상이한 매개효과가 단순히 아버지와 어머니의 양육행동 차이로 해석될 수 없음을 시사한 다. 즉, 아버지와 어머니가 양육에 참여하는 시간이 양적으로 다르기 때문에 질적인 차이로 접근하기 위해서는 주의가 필요 하며, 양육에 많이 참여하는 아버지를 대상으로 한 연구를 통 해 추후 논의가 필요한 부분이다.

아울러 온정적 양육행동의 매개효과와는 별개로 아버지의 사회적 유머는 자녀의 정서 조절능력에 긍정적인 영향을 주는 주요한 변인이다. 아버지의 양육참여가 어머니에 비해 부족하 더라도 아버지 변인이 유아의 발달에 미치는 영향력은 어머니 와 유사하며(Parke, 2000), 오늘날의 아버지들이 친구 같은 아 버지의 모습을 지향함으로써, 자녀와의 친밀한 관계를 만들기 위해 적극적인 상호작용을 시도하고 있음을 반영한 결과라 할 수 있다(H.-S. Cho, Kim, \& Kim, 2008).

본 연구를 통해 부모의 사회적 유머는 유아의 정서 조절능 력에 영향을 미치는 가장 강력한 변인임을 알 수 있다. 사회적 유머는 관계 속에서 나타나는 특징을 가지기 때문에, 유아는 부모의 사회적 유머에 직접적으로 노출된다. 또한 관계를 친 밀하게하기 위한 농담이나 즐거운 이야기는 공격적 유머나 자 기패배 유머 등의 부정적 유머를 이해하기 위한 인지적 과정 을 거치지 않으므로, 유아는 부모의 사회적 유머를 가장 쉽게 이해하고, 받아들일 것이다. 반면, 자기확장 유머는 부모 개인 의 내적인 과정을 통해 형성되는 유머이므로, 유아가 직접적 인 상호작용을 통해 경험할 수 없으며, 유아가 부모의 내적인 측면을 이해하고 해석한다는 것은 오히려 부정적인 유머를 해 석하는 것보다 더욱 높은 수준의 인지 능력이 요구된다. 이와 같은 특성에 따라 모두 긍정적 측면의 유머임에도 불구하고, 자기확장 유머보다 사회적 유머가 특히 유아의 정서조절 능력 에 강력한 영향을 주고 있는 것이다.

이상의 연구결과와 논의를 통해 본 연구는 다음과 같은 의 의를 가진다. 첫째, 부모의 유머스타일이 유아의 정서조절 능 력에 영향을 미치는 요인임을 밝혔다. 특히 최근에 이르러 분 노조절 실패로 인한 우발적 범행이 증가하면서 정서조절 능력 의 발달이 개인의 과제를 넘어 사회적 과제로 주목받고(H. M.

Kim \& Son, 2013; J.-T. Lee, 2016) 있는 만큼 본 연구의 결과는 다양한 함의를 제공하였다.

둘째, 부모의 유머 스타일이 온정적 양육행동에 영향을 미
치는 중요한 변수임을 확인하였다. 그동안 전통적인 한국의 부모상인 엄부자모는 자녀를 훈육하는 기제를 강조하여(You, 1990), 상대적으로 애정 표현의 중요성을 간과하였으나, 현대 사회의 부모들은 친밀감을 높이는 부모자녀 관계를 추구하며, 자녀에 대한 관심과 애정표현에 적극적인 모습을 보이고 있 다. 아울러 온정적 양육행동은 통제적 양육행동과 함께 부모 의 양육행동 유형을 구성하는 기준이며, 바람직한 양육행동이 란 온정적 양육행동과 통제적 양육행동의 수준이 균형을 이루 는 것을 의미(Baumrind, 1973)하므로, 이제는 바람직한 양육 행동을 구성하는 요인이 무엇인지 살피는 것에서 나아가 온정 적 양육행동을 어떻게 키워나가야 할 것인가를 논의하고 실천 적으로 부모교육에 적용해야 할 시점이라 여겨진다.

부모교육의 현장에서 부모의 유머사용이 유아의 긍정적인 정서발달과 더불어 온정적인 양육행동의 효과를 높이기 위한 실천적 양육기술로 활용되기를 기대해본다.

\section{Notes}

This article is a part of the first author's doctoral dissertation submitted in 2017, and was presented as a poster at the 2018 Annual Spring Conference of the Korean Association of Child Studies.

\section{Conflict of Interest}

No potential conflict of interest relevant to this article was reported.

\section{References}

\section{In English}

Alegre, A. (2011). Parenting styles and children's emotional intelligence: What do we know? The Family Journal, 19(1), 56-62. doi:10.1177/1066480710387486

Baron, R. M., \& Kenny, D. A. (1986). The moderator-mediator variable distinction in social psychological research: Conceptual, strategic, and statistical considerations. Journal of Personality and Social Psychology, 51(6), 1173-1182. doi:10.1037//0022-3514.51.6.1173

Baumrind, D. (1973). The development of instrumental competence through socialization. In A. D. Pick (Ed.), Minnesota Symposia on Child Psychology: Volume 7 (pp. 3-46). Minneapolis, MN: 
University of Minnesota Press. doi:10.5749/j.ctttsmk0.4

Belsky, J. (1984). The determinants of parenting: a process model. Child development, 55(1), 83-96. doi:10.2307/1129836

Causey, D. L., \& Dubow, E. F. (1992). Development of a selfreport coping measure for elementary school children. Journal of Clinical Child and Adolescent Psychology, 21(1), 47-59. doi:10.1207/s15374424jccp2101_8

Dodge, K. A., \& Garber, J. (1991). Domains of emotion regulation. In J. Garber \& K. A. Dodge (Eds.), The development of emotion regulation and dysregulation (pp. 3-12). Cambridge, UK: Cambridge University Press. doi:10.1017/cbo9780511663963.002

Eisenberg, N., Liew, J., \& Pidada, S. U. (2001). The relations of parental emotional expressivity with quality of Indonesian children's social functioning. Emotion, 1(2), 116-136. doi:10.1037//1528-3542.1.2.116

Freud, S. (1976). The pelican Freud library: Vol. 6. Jokes and their relation to the unconscious (J. Strachey Ed.). Harmondsworth, NY: Penguin.

Kochanska, G., Aksan, N., \& Carlson, J. J. (2005). Temperament, relationships, and young children's receptive cooperation with their parents. Developmental Psychology, 41(4), 648660. doi:10.1037/0012-1649.41.4.648

Martin, R. A. (2006). Sense of humor and physical health: Theoretical issues, recent findings, and future directions. Humor-International Journal of Humor Research, 17(1-2), 1-19. doi:10.1515/humr.2004.005

Martin, R. A., Puhlik-Doris, P., Larsen, G., Gray, J., \& Weir, K. (2003). Individual differences in uses of humor and their relation to psychological well-being: Development of the humor styles questionnaire. Journal of Research in Personality, 37(1), 48-75. doi:10.1016/s00926566(02)00534-2

Mayer, J. D., \& Salovey, P. (1995). Emotional intelligence and the construction and regulation of feelings. Applied and Preventive Psychology, 4(3), 197-208. doi:10.1016/s09621849(05)80058-7

McGhee, P. E. (1976). Children's appreciation of humor: A test of the cognitive congruency principle. Child Development, 47(2), 420-426. doi:10.2307/1128797

Morris, A. S., Silk, J. S., Steinberg, L., Myers, S. S., \& Robinson, L. R. (2007). The role of the family context in the development of emotion regulation. Social Development, 16(2), 361-388. doi:10.1111/j.1467-9507.2007.00389.x

Parke, R. D. (2000). Father involvement: A developmental psychological perspective. Marriage \& Family Review, 29(23), 43-58. doi:10.1300/j002v29n02_04

Pett, M. A., Vaughan-Cole, B., \& Wampold, B. E. (1994). Maternal employment and perceived stress: Their impact on children's adjustment and mother-child interaction in young divorced and married families. Family Relations, 43(2), 151-158. doi:10.2307/585317

Shield, A., \& Cicchetti, D. (1997). Emotion regulation among school-age children: The development and validation of a new criterion Q-sort scale. Developmental psychology, 33(6), 906-916. doi:10.1037/0012-1649.33.6.906

Teti, D. M., \& Candelaria, M. A. (2005). Parenting competence. In M. H. Bornstein (Ed.), Handbook of parenting: Volume 4 social conditions and applied parenting (pp. 149-180). Mahwah, NJ: Psychology Press.

Thompson, R. A. (1994). Emotion regulation: A theme in search of definition. Monographs of the Society for Research in Child Development, 59(2-3), 25-52. doi:10.2307/1166137

\section{In Korean}

Baek, M. A. (2002). Children's affective perspective-taking and emotion regulation to parents' emotional expressiveness (Master's thesis). Retrieved from http://www.riss.kr/ link?id=T9005117

Cho, B. H., Lee, J. S., Lee, H. S., \& Kwon, H. K. (1999). Dimensions and assessment of Korean parenting style. Journal of the Korean Home Economics Association, 37(10), 123-133.

Cho, H.-S., Kim, J.-H., \& Kim, T.-I. (2008). Images of father pursued by the fathers of young children. Early Childhood Education Research \& Review, 12(1), 239-264.

Choi, H.-J., \& Gwag, H.-M. (2017). The Influence of children's emotional control skills and social competence on adaptation to early childhood education institutes: With emphasis on gender and age difference. The Journal of Korea Open Association for Early Childhood Education, 22(3), 145-168. doi:10.20437/koaece22-3-07

Ha, S. S., \& Kwon, S. M. (2011). Influence of temperament and perceived parenting styles on character strengths: Focusing on the mediating effect of perceived parenting styles. The Korean Journal of Clinical Psychology, 30(1), 263-284. doi:10.15842/kjcp.2011.30.1.014

Hur, Y. (2010). Humor sense and humor style of pre-service teacher and change of teacher education. The Korean Journal Of Educational Methodology Studies, 22(2), 19-49.

Jeon, H. J., \& Park, S. Y. (1999). Childhood experience, personality, and marital satisfaction: Relationship to parenting behaviors. Korean Journal of Child Studies, 20(3), 153-169.

Kim, H. M., \& Son, C. N. (2013). Effects of anger control program on anger, interpersonal relationship and self-esteem for people with mental disability in rehabilitation center. The Korean Journal of Stress Research, 21(2), 109-119.

Kim, J.-Y. (2004). A qualitative study on children's humor and friendships. Journal of Early Childhood Education, 24(6), 113-133. 
Kim, J. Y. (2007). Problem behavior of preschool children: The influence of marital conflict and of children's temperament and emotion regulation (Master's thesis). Retrieved from http://www.riss.kr/link?id=T11038811

Kim, J.-Y., \& Chung, K.-S. (2013). Relations between sense of humor, stress coping style, and parenting stress of preschooler's mother. Journal of Life-span Studies, 3(1), 59-77.

Kim, J.-Y., \& Lee, J.-S. (2011). Mediating effect of depression between alcohol use factors and child maltreatment with married female employees. Family and culture, 23(3), 93125. doi:10.21478/family.23.3.201109.004

Kim, M. J. (2006). Effect of mother's parenting behavior and children's emotional regulation on children's aggression (Master's thesis). Retrieved from http://www.riss.kr/link?id= T10360589

Kim, Y.-H. (2009). Cultural technical exploration on infants' humor characteristics and contextual elements and meanings of humor in peer relationship. The Journal of Eco-Early Childhood Education, 8(3), 151-174.

Lee, J.-T. (2016). Development of a parent education program to improve anger control ability of parents of elementary school children. The Journal of the Korea Contents Association, 16(5), 668-685. doi:10.5392/jkca.2016.16.05.668

Lee, J.-U., Choi, H.-H., \& Bak, B.-G. (2012). A meta-analysis of the relationship between parental rearing style and developmental characteristics of children. The Journal of Child Education, 21(4), 275-296.

Lee, J.-W., \& Kang, E.-J. (2014). Effects of infant children mothers' humor and ego resilience on maternal behavior. Journal of the Korea Academia-Industrial Cooperation Society, 15(11), 6576-6586. doi:10.5762/kais.2014.15.11.6576

Lee, S. W., Moon, J. S., \& Kim, Y. H. (2012). Effects of mother's verbal control modes and young children's emotional regulation on young children's social competence. Journal of Future Early Childhood Education, 19(1), 283-305.

Lee, Y., Kim, A., \& Lim, J. (2016). Abeoji yangyukchamyeo siltae mit yeongnyang Ganghwa bangan [아버지 양육참여 실태 및 역량 강화 방안] (Report No. 2016-16). Retrieved from KICCE website: http://www.kicce.re.kr

Lim, H. S., \& Park, S. Y. (2002). Child's sex, temperament, mother's emotion regulation and parenting as related to child's emotion regulation. Korean Journal of Child Studies, 23(1), 37-54.

Lim, Y. (2002). Children's peer competence in relation to maternal parenting styles and children's emotion regulation. Family and Environment Research, 40(1), 113-124.

Lim, Y., \& Jin, M. (2015). The mediating effects of children's emotional regulation ability on the relationship between children's perception of parenting attitudes and peer relationships. Korean Journal of Play Therapy, 18(4), 348367. doi:10.17641/kapt.18.4.4

Park, H. R. (2001). Psychological structures of experience of humor appeal advertising by humor-formation mechanisms. The Korean Journal of Advertising, 12(4), 37-72.

Park, I. S., \& Nam, E. Y. (2015). Relations among coparenting, father involvement in child-rearing, and toddler's emotion regulation. The Korean Journal of Developmental Psychology, 28(4), 135-153.

Park, J. H. (2001). Children's peer competence in relation to maternal parenting goals, parenting behaviors, and management strategies of peer relations (Doctoral dissertation). Retrieved from http://www.riss.kr/link?id=T7912822

Park, S. J. (2004). Relations between maternal socialization behaviors of emotions and school-aged children's competence and strategies of emotion regulation (Doctoral dissertation). Retrieved from http://www.riss.kr/link?id=T9832780

Shin, B.-J., Kim, H.-S., \& Lee, M.-H. (2010). Effect of humorous video tape on depression and stress response in patients undergoing hemodialysis. Journal of East-West Nursing Research, 16(1), 35-43.

Son, Y.-J., \& Park, S.-Y. (2011). The relationship between parenting stress and parenting behavior: The moderating effect of the mother's personality. The Korean Journal of Human Development, 18(2), 125-144.

Yeo, E. J., \& Lee, K. O. (2009). A structural analysis of the relationships among children's emotionality, mother's emotionality, mother's emotion-related socialization behaviors and children's emotion regulation. The Journal of Korea Open Association for Early Childhood Education, 14(5), 275-295.

You, A. (1990). Hanguk jeontongsahoeui yuagyoyuk [한국 전통사회 의 유아교육]. Seoul: Seoul National University Press.

\section{ORCID}

Yeon Kyeung Oh

Hae Shin Hwang https://orcid.org/0000-0001-8199-0306

https://orcid.org/0000-0002-2905-354X

Revision received December 20, 2018

Accepted January 21, 2019
Received October 31, 2018 